\title{
Squamous Cell Carcinoma of the Urinary Bladder: Clinicopathological and Molecular Update
}

\author{
Sunil Vitthalrao Jagtap ${ }^{1}$, Swati S Jagtap ${ }^{2}$, Parneet Kaur ${ }^{1}$, Snigdha Vartak ${ }^{1}$
}

Cite this article: Jagtap SV, Jagtap SS, Kaur P, Vartak S: Squamous Cell Carcinoma of the Urinary Bladder: Clinicopathological and Molecular Update. Ann Urol Oncol 2021; 4 (1): 10-17.https://doi.org/10.32948/auo.2021.10.11

\begin{abstract}
Urinary bladder cancer is one of the most prevalent cancers worldwide.Squamous Cell Carcinoma (SCC) is an uncommon subtype of urinary bladder carcinoma. It is a malignant epithelial neoplasm arising in the urinary bladder demonstrating a pure squamous cell phenotype. On histopathology it is considered when tumor is showing pure squamous morphology without any component of conventional urothelial carcinoma. The SCC is a histologically distinct form of cancer. It arises from the uncontrolled multiplication of cells showing particular cytological or tissue architectural characteristics of squamous cell differentiation, such as the presence of keratin, tonofilament bundles or desmosomes. Majority of bladder SCC are high grade, high stage tumors with most cancers having muscle invasion at the time of diagnosis while overall about $80 \%$ of bladder cancers are non-muscle invasive bladder cancer at diagnosis.COX-2 is markedly expressed in all SCCs. An increased COX2 level induces the development of SCC of the bladder affecting many biological features of this tissue including apoptosis, cell adhesion, angiogenesis and invasiveness.TERT promoter mutations, commonly found in conventional urothelial carcinoma, are also highly prevalent in urinary bladder squamous cell carcinoma suggesting a common tumorgenesis and potential utility as a molecular urine-based-screening assay. This review summarizes the current features related to clinical , pathological, and molecular features of SCC of urinary bladder.
\end{abstract}

Key words Urinary bladder cancer, Squamous cell carcinoma, Pathology, Molecular biomarkers

\footnotetext{
1. Department of Pathology, Krishna Institute of Medical Sciences, Deemed University, Karad-415110, India.

2. Department of Physiology, Krishna Institute of Medical Sciences, Deemed University, Karad-415110, India.

Correspondence: Sunil Vitthalrao Jagtap (Department of Pathology, Krishna Institute of Medical Sciences, Deemed University, karad-415110, Maharashtra, India; Email: drsvjagtap@gmail.com).
} 


\section{Introduction}

The SCC of the bladder is a rare histopathological variant. These tumors shows very aggressive clinical behavior as compared to conventional urothelial carcinoma. The urinary bladder cancer is the most common malignancy of the urinary tract, accounting for about 77,000 new cases and 16,000 deaths/year in the USA [1]. The transitional cell carcinoma has higher incidence, and therefore it has received the most research attention.

The squamous cell lesions in urinary bladder include squamous papilloma,squamous metaplasiawhile malignant tumors are pure squamous cell carcinoma, urothelial carcinoma with squamous differentiation, basaloid SCC, verrucous carcinoma and warty carcinoma. Pure Squamous Cell Carcinoma (SCC) of the bladder generally represents $2 \%$ to $7 \%$ of all urothelial cancers with considerable geographic variability in prevalence worldwide [2].

It is observed that SCC is the second most common cell type associated with bladder cancer in industrialized countries. Pure SCC is the most common non-urothelial variant, accounting 5\% of all bladder cancers in western countries and reaching 30\% in Schistosoma haematobium endemic regions like Egypt and Sudan [3]. SCC is the most common form of bladder cancer, accounting for $75 \%$ of cases in developing nations [4]. Urinary bladder cancer based on the degree of invasion in the bladder muscle are classified into non-muscle invasive or muscle invasive cancer, which is important in patient management. This article is useful for understanding theclinicopathological feature and molecular subtypes in urinary bladder cancers and important in specific therapeutic strategies.

\section{Discussion}

The urinary bladder cancer is the fourth most common malignant tumor in the United States.The fourth edition of the World Health Organization (WHO) classification of urogenital tumors, published in 2016 has given various histopathological variants. About 90 $95 \%$ of bladder cancers exhibit conventional urothelial carcinoma (transitional cell carcinoma)on the histopathological features. About $5-10 \%$ of tumors contain other and rare histological variants like plasmacytoid, signet ring, sarcomatoid, giant cell, lipid rich, clear cell, neuroendocrine, sarcomatoid, squamous cell

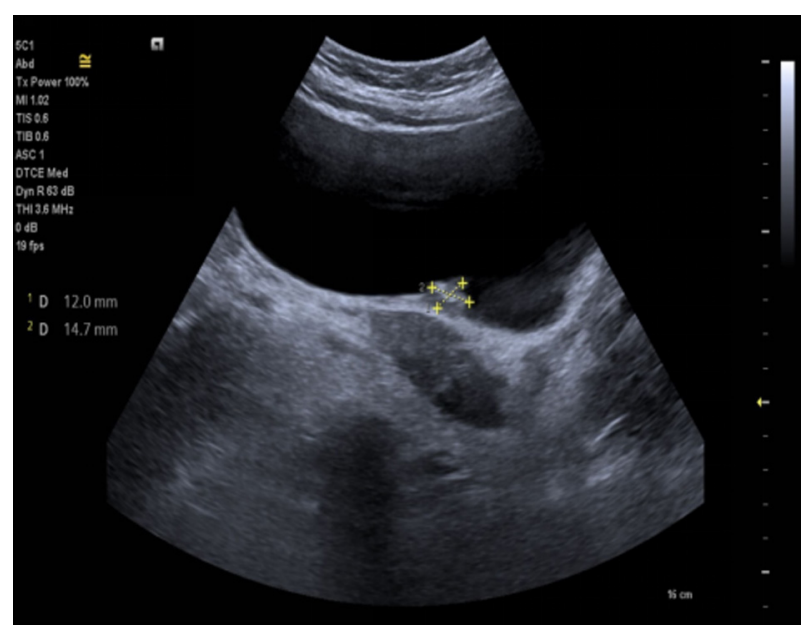

Figure 1: Ultrasonography bladder showed irregular thickened urinary bladder wall. carcinoma, small cell carcinoma etc [5].

The various differentiation in conventional urothelial carcinoma of transitional cell carcinoma noted are squamous, glandular, trophoblastic etc [6]. The squamous variant is the most common divergent differentiation, counting up to $40 \%$ of invasive urothelial carcinoma.

Based on etiological factors the SCC is divided into two subtypesa) SCC associated with bilharzia infection (schistosomiasis), i.e. Bilharzial-associated SCC (B-SCC). b)SCC not associated with bilharziasis, i.e. Non-Bilharzial-associated SCC (NB-SCC).

B-SCC and NB-SCC differ in their epidemiology, natural history, and clinicopathological features (Table 1).

Overall the various known risk factor for urothelial carcinomas are chronic cystitis, mostly related to schistosomiasis,vitamin A deficiency,systemic therapy with cyclophosphamide, smoking,etc. Schistosomiasis is considered the major predisposing factor for B-SCC .The schistosomiasis endemic regions are mostly observed in the Middle East, Southeast Asia, and South America. Santos LL et.al. studied historical perspective of schistosomiasis, and review the infection-associated pathological mechanisms underlying schistosomiasis-associated carcinogenesis [7]. B-SCC and NB-SCC differ in their epidemiology, natural history, and clinicopathological features. Patients with NB-SCC are generally diagnosed at a late stage and present with poor prognosis. Approximately $70 \%$ of pure SCCis muscle-invasive at initial diagnosis, with high rate of local recurrence. In Western countries, where NB-SCC is the predominant subtype, patients are typically diagnosed in the seventh decade and have poor survival outcomes.

\section{Squamous Cell Carcinoma etiology}

For SCC, age group affected is mostly in seventh decade.The association between chronic bladder irritation and SCC has been postulated, which include chronic or recurrent urinary tract infection, long term catheterization, neurogenic bladder, bladder calculi, foreign bodies, prolonged exposure to cyclophosphamide, extrophy of urinary bladder [8], [9].

It is observed that the long-standing bladder stones have been implicated as a cause of squamous cell carcinoma of the bladder [10]. It is also noted that large bladder stone are associated with an aggressive squamous cell carcinoma of the bladder [11].

The various urinary tract infectionsrelated tobacteria includes Escherichia coli, Proteus, and Streptococcus faecalis. These have been implicated in the development of squamous metaplasia. The carcinogenic mechanism probably involves nitrosamine production and release of free carcinogenic products through secretion of $\beta$-glucoronidase. Also it has been noted that human papilloma virus has been linked to genitourinary cancers and SCC.

Tobacco smoking has been reported as a major risk factor for bladder cancer in both SCC and transitional cell carcinoma. The pathogenesis for all above mentioned etiological factors are thought to create an environment abundant in growth factors and cytokines favouring cell proliferation, migration, angiogenesis, and inhibition of apoptosis, resulting in squamous metaplasia, dysplasia, and cancer [12].

\section{Clinical features of SCC}

SCC occurs most often in the seventh decade with a slight male predominance. Clinical features of SCC include haematuria, urgency, frequency, and obstruction. Most of the patients with SCC of the bladder present with haematuria. Haematuria is the leading sign motivating to suspect the urinary bladder cancer detection. The most of the patients, up to $93 \%$ presents with chronic cystitis and recurrent urinary tract infection. The rare cases of SCC of the 


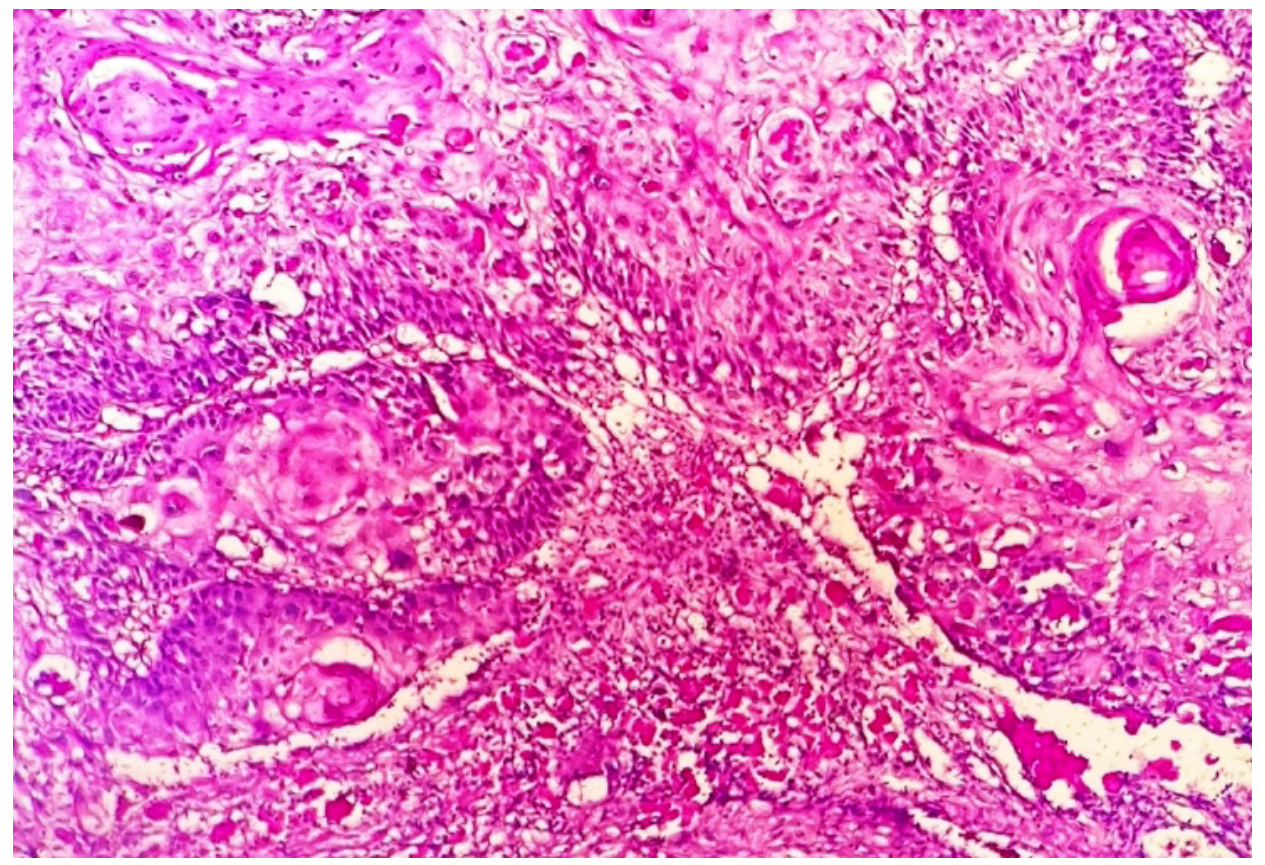

Figure 2: Photomicrograph showing squmous tumor cells arranged in sheets, irregular infiltrating nests with formation of keratin pearls, keratinization and intercellular bridges. (Haematoxylin\&Eosin stain, 100x).

bladder presenting with bladder rupture were noted [13].

The recommendations on diagnostic issues the various investigations and diagnostic procedures carried include urine cytology, radioimaging like CT or MRI which may be used for location of tumor,sizeof tumor, staging, depth of tumor invasion. The diagnostic procedures like cystoscopy, biopsy and transurethral resection of bladder masshave significant role. The advance techniques includesimmunohistochemistry, molecular biomarkers etc.

On cystoscopy, tumors are predominantly ulcerative and commonly located at upper vesical hemisphere, trigone and lateral walls. The tumors are predominantly nodular or ulcerative type

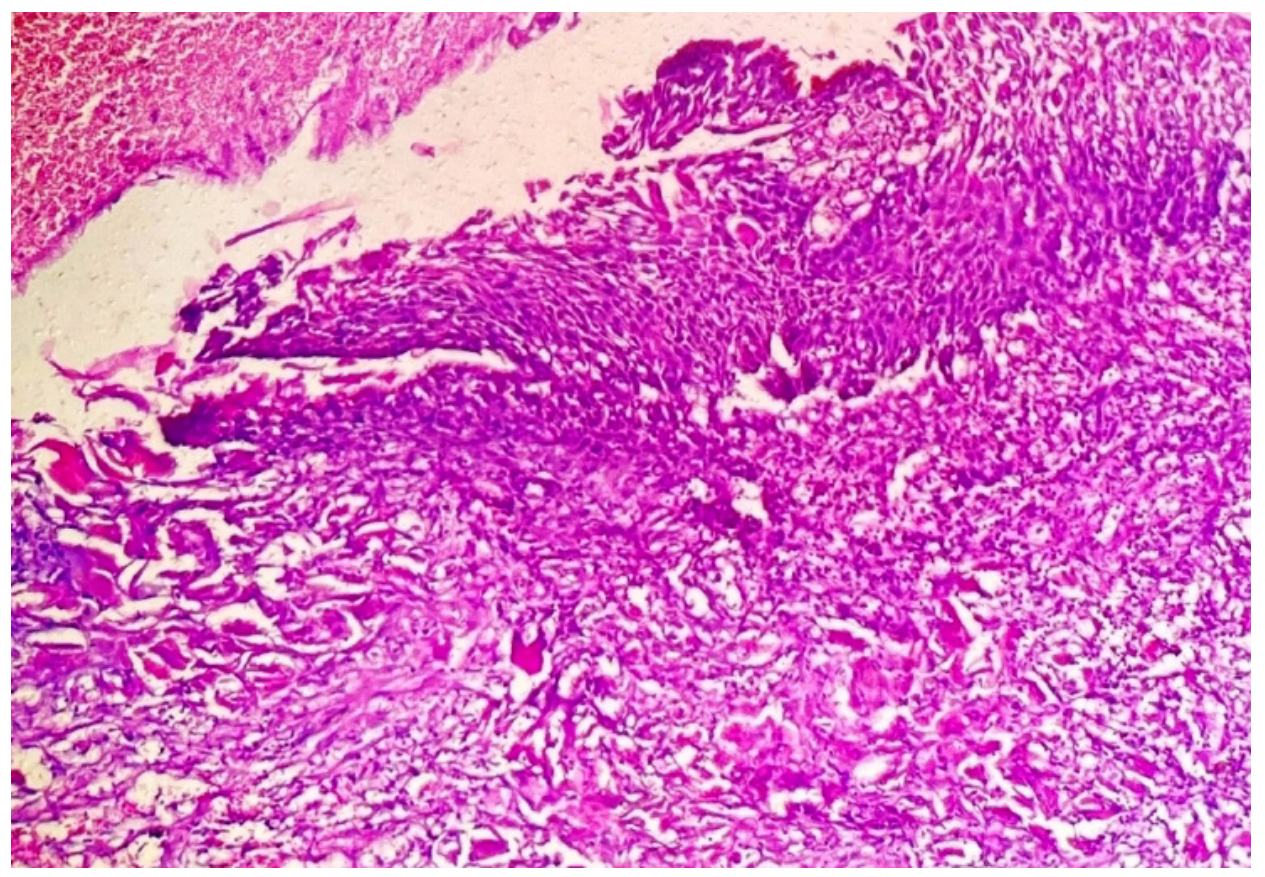

Figure 3: Photomicrograph showing invasive squmous cell carcinoma. (Haematoxylin \& Eosin stain, 100x). 
Table 1. Differences between Biharzial infestation and Non- Biharzial in the development of urinary bladder SCC.

\begin{tabular}{|c|c|c|}
\hline Clinical, lab investigations & B - SCC & NB - SCC \\
\hline Occurrence of bladder tumors in & $20-30 \%$ & $2-5 \%$ \\
\hline Age & $40-50$ years & $60-70$ years \\
\hline Gender Male: Female & $5: 1$ & $3: 2$ \\
\hline Endemic geographical reagions & $\begin{array}{l}\text { Eastern and South East } \\
\text { Asia, } \\
\text { South America }\end{array}$ & Western countries \\
\hline Predisposing factors & $\begin{array}{l}\text { Biharzial infection, } \\
\text { Urinary tract infections }\end{array}$ & $\begin{array}{l}\text { Catheters, } \\
\text { Bladder irrirants, } \\
\text { Recurrent urinary tract infections }\end{array}$ \\
\hline On cystoscopy & Growth -nodular & Ulcerative/infiltrative \\
\hline Symptoms & IrritableBladder, Hematuria & Hematuria \\
\hline $\begin{array}{l}\text { Biochemical serum tumor markers- } \\
\text { XO,LDH,AST,ALT, IgE, TNF- } \alpha\end{array}$ & More Raised & Less raised \\
\hline Immunohistochemical expression in SCC & $\mathrm{Ck} 5+/ \mathrm{CK} 20-$ & $\mathrm{Ck} 5+/ \mathrm{CK} 20+$ \\
\hline Stage & Advanced & Advanced \\
\hline Grade & $50 \%$ Low Grade & High Grade \\
\hline Lymph Node Metastasis & $18 \%$ & $8-10 \%$ \\
\hline Standard Treatment & Radical Cystectomy & Radical Cystectomy \\
\hline Prognosis & good & poor \\
\hline Recurrence & Mostly Local & Mostly Local \\
\hline Prevention & $\begin{array}{l}\text {-Snail control } \\
\text {-anti Bilharzial Drugs } \\
\text { Early dignosis }\end{array}$ & $\begin{array}{l}\text { Avoidance of bladder irritants and } \\
\text { prolonged catheterization }\end{array}$ \\
\hline
\end{tabular}

Biharzial Squamous Cell carcinoma =B SCC, Non- Biharzial Squamous Cell Carcinoma $=$ NB SCC, Xanthine Oxidase $=($ XO), Lactate dehydrogense $=(\mathrm{LDH})$, Aspartate aminotransferase $=($ AST $)$, Alanine aminotransferase $(\mathrm{ALT})$, total immunoglobulin $\mathrm{E}$ $=(\operatorname{IgE})$ and Tumor Necrosis Factor alpha $=(\mathrm{TNF}-\alpha)$.

with thickened wall. In late stages SCC tumors are typically large, solitary masses, and associated with leucoplakia.

\section{Gross Pathological Features of SCC}

On gross histomorphological examination, the tumors areusually large, sessile or exophytic, bulky tumors. In few cases, predominantly flat with ulcerating type are noted. The infiltrating type at the time of diagnosis is also commonly noted. They often show the necrotic areas with flaky keratin material on the surface. We reported a case of 70-year-old male patient presented with reduced frequency of micturition, pain during micturition, hematuriaand gradually developing retention of urine for three months duration. Ultrasonography bladder showed irregular thickened urinary bladder wall [Figure 1]. On Contrast Enhanced CT scan abdomen-pelvis showed bladder wall with well defined isodense to hyperdense, lobulated, non pedunculated mass lesion with irregular margins and heterogeneous enhancement with multiple low alternating areas in mass lesion suggestive of necrosis. On histopathology examination showed tumor composed of neoplastic squamous cells arranged in epithelial fronds and large sheets. Individual cells were large polygonal having moderately pleomorphic hyperchromatic to vesicular nuclei, occasional nucleoli and mild to moderate amount of eosinophilic cytoplasm [Figure 2, 3, 4, 5]. Numerous keratin pearls along with individual cell keratinisation was noted. It was moderate grade squamous cell carcinoma with muscle invasion. On radiological evaluation showed internal iliac group of nodal involvement. According to WHO/ISUP classification of tumors of urinary bladder 2004, our case was invasive neoplasm-SCC grade II and stage T2N1M1 [14].

\section{Microscopic features of SCC urinary bladder}

The SCC tumors are well, moderately or poorly differentiated. The neoplastic cells are squamous cells with destructive stromal invasion. The malignant squamous tumor cells arearranged in sheets, irregular infiltrating nests, or scattered. These cells show differentiation in the form of keratin pearls, individual cell keratinization or intercellular bridges. Eble JN et al and Manuta A et al showed that there is usually surface keratinizing squamous metaplasia and dysplasia or squamous carcinoma in situ [15], [16].SCC is described as an epithelial neoplasm exclusively 


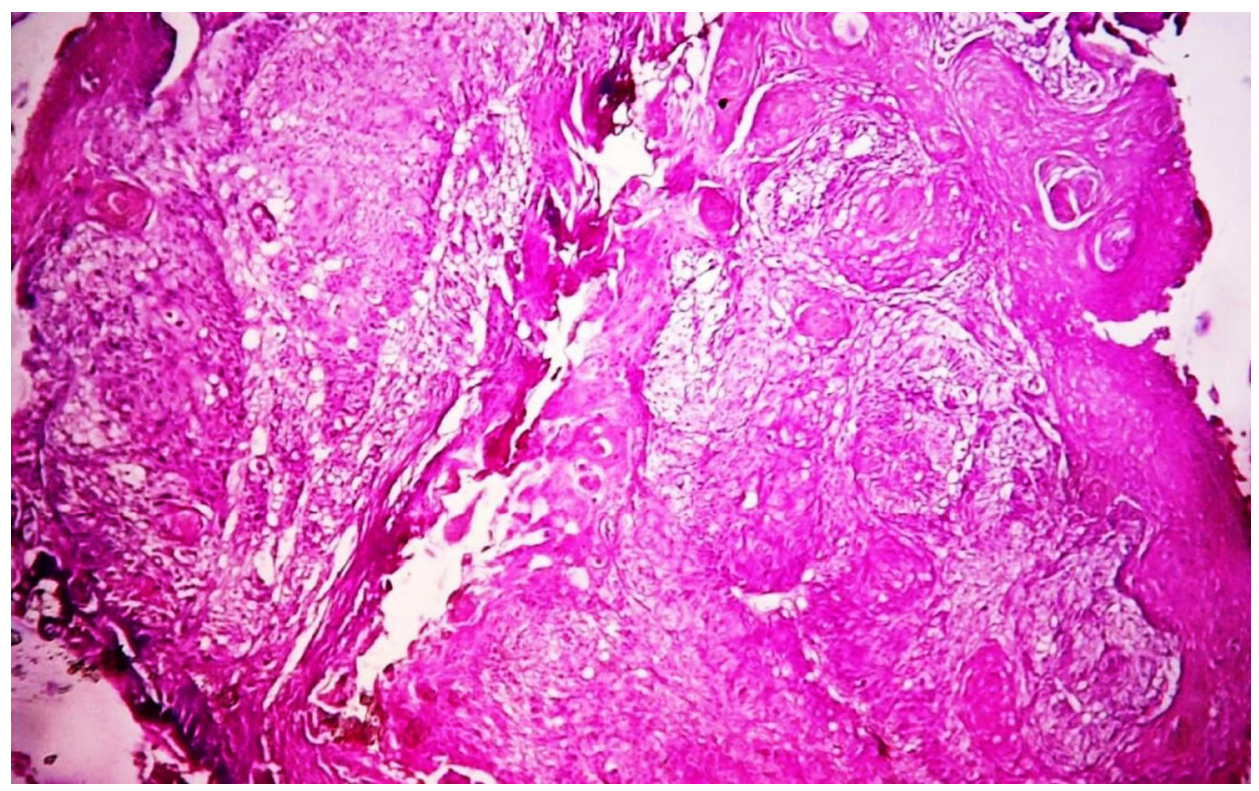

Figure 4: Photomicrograph showing well to moderately differentiated squmous cell carcinoma with muscle invasion. (Haematoxylin \& Eosin stain, 100x).

displaying histological hallmarks such as squamous keratin pearls, intercellular bridges, keratin cellular debris and keratohyalin granules [17].

Although squamous features are present in TCC variants with mixed histology, the definition of SCC or pure SCC is reserved for tumors that only contain squamous components without any evidence of urothelial components. If any component of conventional urothelial carcinoma or urothelial carcinoma in situis present, even focally, tumor is designated as urothelial carcinoma with squamous differentiation.

The differential diagnosis are urothelial carcinoma with squamous differentiation,verrucous carcinoma and secondary spread of squamous cell carcinoma primary to another site, e.g. cervix, penis, anus. In difficult condition, the distinction requires evaluation of the entire resected tumor. In addition, careful clinical,imaging techniques correlation is advised to ensure the

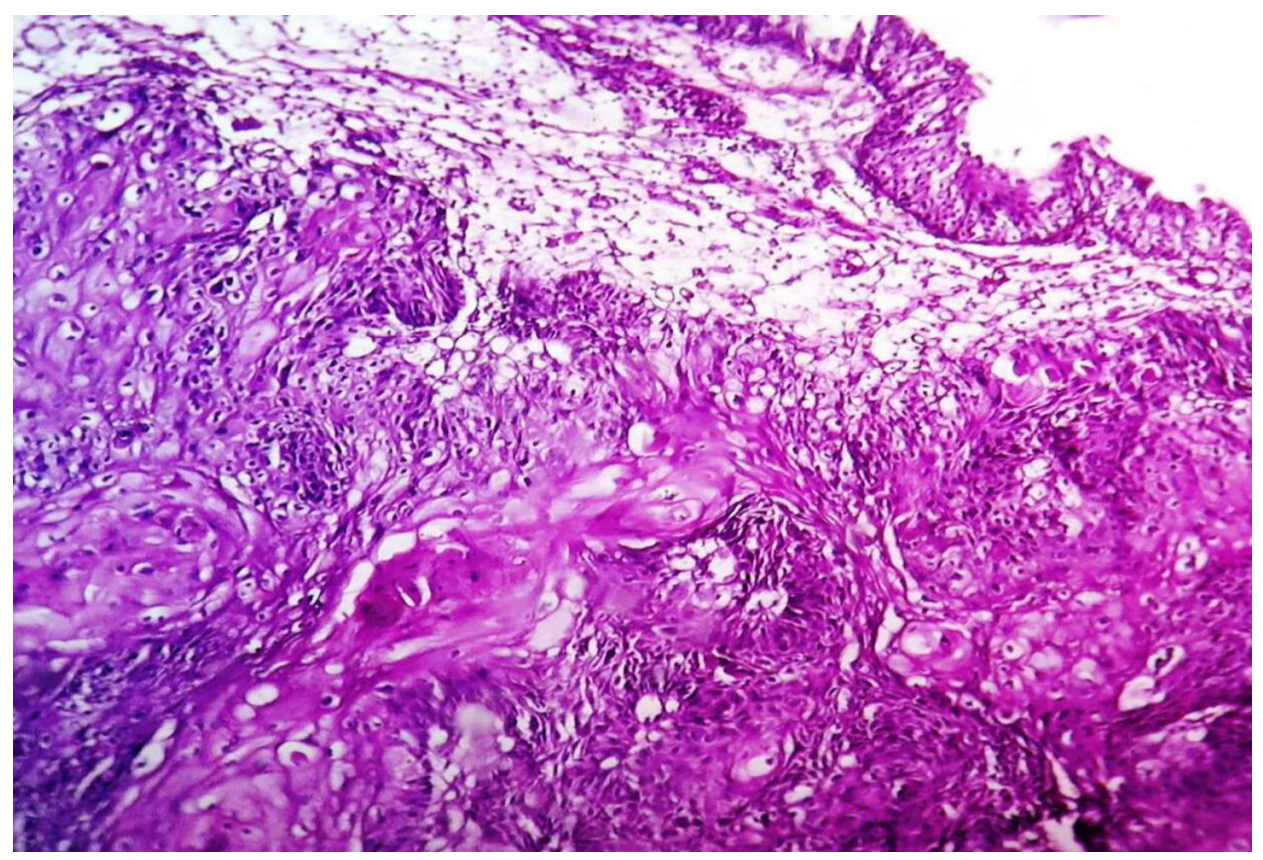

Figure 5: Photomicrograph showing squmous cell carcinoma. The urothelium is normal. (Haematoxylin \& Eosin stain, 100x). 
tumor is compatible with a bladder primary or metastatic origin.In verrucous carcinoma tumor is well differentiated with "pushing" border in lamina propria,no infiltrating nests of tumor is noted. Pure verrucous carcinoma has better prognosis with no metastatic risk.The pathological prognostics of SCC include tumor stage, grade, lymphovascular, and presence of lymph nodeinvolvement . [18], [19].

\section{Immunohistochemical (IHC) markers of SCC urinary bladder}

The various IHC markers have been studied for SCC. The $\mathrm{SCC}$ is positive for squamous markers likeCK5, CK6, while variable for CK7. Also these shows positivity for p63, p40, CK14 and desmoglein-3 [20]. Mariah Z et al study showed these are with reduced expression of urothelial markers like uroplakin, GATA3, S100P [21]. Gulmann C et al observed that pure squamous cell carcinomas were positive for CK14 (100\%) and desmoglein-3 (75\%), negative for GATA3 and uroplakin III in their study [22].

Dalia R Al-Sharaky et al, observed that most squamous cell carcinoma and those associated with bilharziasis were belonged to $\mathrm{Ck} 5+/ \mathrm{CK} 20$ - subgroup while pure UC and those lacked bilharziasis were located in the $\mathrm{Ck} 5+/ \mathrm{CK} 20+$ subgroup [23].

IHC observations demonstrate that about $67 \%$ of bladder cancers with squamous differentiation express EGFR. Wenbin Huang observed that MAC387, desmoglein-3, and TRIM29 antibodies demonstrated positive staining in pure SCC and urothelial carcinomas with squamous differentiation [24].

\section{Molecular biomarkers of SCC urinary bladder}

The overall molecular pathways for invasive urothelial tumors develop via either high-grade papillary tumors or CIS [25]. The molecular alterations differ markedly between low- and highgrade tumors [26]. It also differs in invasive and noninvasive types. The recurrent mutations occur in genes such as TP53, FGFR3, PIK3CA, RB1,HRAS, and promoter mutations of TERT [27]. TERT promoter mutations (TERT-mut) are detectable in the majority of urothelial carcinomas. The TERT mutations are present in up to $79 \%$ of bladder neoplasms;its presence is of great diagnostic value $[28,29]$ Cowan $\mathrm{M}$ et al performed sequencing for TERT-mut using SafeSeq technique, study detected TERT-mut in 12/15 of bladder squamous cell carcinomas [30].

While specific to SCC the exact pathophysiologic mechanism of the transformation from keratinizing squamous metaplasia to SCC is not clearly understood. It is studied that the transformation is mediated by the epithelial growth factor (EGFR) a tyrosine kinase that transduces signals controlling cell proliferation. The rapid clinical course, lymphovascular invasion,lymph node metastasis, and aggressive pathological features of SCC are associated withfibroblast growth factor 2 (FGF-2) overexpression.

It is observed that the cyclooxygenase $2(\mathrm{COX}-2)$ alterations were associated with higher stage and grade in both NB-SCC and B-SCC. It is considered therefore of having poor outcomes in these cases.The pathogenesis behind chronic inflammation is that it stimulates the production of COX-2 protein. An increased COX-2 level in turn induces the development of SCC of the bladder affecting many biological features of this tissue including apoptosis, cell adhesion, angiogenesis and invasivenessof the tumor. Tsutomu S and Chohei Sstudy showed that COX-2 protein is overexpressed in SCC of the urinary bladder. To reduce the incidence of SCCs, it is therefore important to inhibit COX-2 at the level of the enzyme as well as at the level of gene expression to inhibit peroxidase activity of COX-2 [31].

In SCC tumors Human epidermal growth factor receptor 2 (HER2) oncoprotein expression was also recently identified to be higher

\section{expression.}

Study from Dotson A et al noted SCC and tumor with squamous cell differentiation shows basal keratin expression. This subtype expresses high levels of basal markers like CD44, KRT5, KRT6A and KRT14 [32]. Squamous cell differentiation markers are TGM1, DSC3 and PI3 and immune markers PD-L1 and CTLA4. This subtype frequently has a high carcinoma in situ score, and presence of TP53 mutations [33].

In contrast to urothelial carcinoma more rate of chromosome $9 \mathrm{p}$ allelic loss and CDKN2 tumor suppression gene alterations have been noted in SCC urinary bladder [34].

Maia MC et al reviewed the available data on biomarkers of bladder SCC and provide suggestions on how these may influence therapeutic testing and clinical trials in the future [35].

The study by Ewis AA et al observed that the genes were upregulated in SCC of the bladder, including matrix degradationrelated genes, growth factors, different oncogenes, and immunology related genes. Conversely, 44 genes were downregulated in SCC of the bladder, including integrins, laminins, cadherins, nonmetastatic cell 1 (NM23) and apoptosis-related genes [36].

Additional prospective studies are needed to determine whether the molecular subtype can predict the response to therapies.

\section{Treatment of SCC of urinary bladder}

The radical cystectomy and urinary diversion is the standard treatment of SCC of the urinary bladder. The SCC often presents at an advanced stage; however, radical cystectomy with lymph node dissection appears to offer a significant benefit in survival in a subset of patients.

The 'gold standard' treatment for SCC is radical cystectomy, but other management strategies are use of radiotherapy and chemotherapy in the neoadjuvant or adjuvant setting have been employed with varying successes. Roleof neoadjuvant chemotherapy in pure SCC is uncertain. The European Association of Urology has released updated guidelines on Non-muscleinvasive Bladder Cancer (NMIBC). Stratification of patients into low-, intermediate-, and high-risk groups is essential for decisions about adjuvant intravesical instillations. Risk tables can be used to estimate risks of recurrence and progression [37]. Unlike urothelial cell carcinoma, SCC is resistant to chemotherapy and guidelines recommend radical cystectomy without neoadjuvant chemotherapy.Dotson A et al study on analysis of a national tumor registry suggests a lack of overall survival benefit for neoadjuvant chemotherapy with localized, muscle invasive SCC of the bladder [32 ]. Immunotherapy has proven to offer clinical responses in patients with platinum-refractory metastatic TCC and may represent as well a new treatment option for non-urothelial carcinomas including SCC.

\section{Prognosis of SCCof urinary bladder}

SCC had a more rapid disease progression than TCC. The SCC patients often present at advanced stage at diagnosis resulting in poor prognosis. The outcome can be improved by early detection with frequent cytology, cystoscopy and biopsy studies. A study by Manunta A et al showed the overall prognosis of NB-SCC is poor, with most patients dying within 3 years and a 5 -year survival rate of $33-48 \%$ [17 ]. The application of molecular biomarkers in prognosis is limited because of the expenses and inconvenience.

Surveillance, Epidemiology, and End Results (SEER) program showed that the most frequent stage was T3 (42.3\%), and the most common histological grades were II (37.3\%) and III (42.5\%). These findings support that NB-SCC tumors are locally advanced with a moderate-to-high histological grade, in contrast to tumors 
of B-SCC, which are similarly advanced but are usually well differentiated [38].

The prognosis in SCC is very poor regardless of degree of differentiation. A study by Matulay JTet al observed that invasive SCC of the bladder carries a worse prognosis as compared to urothelial carcinoma, both overall and on a stage-for-stage basis [39].

In SCC $>50 \%$ death occurs in the first year. Five year survival rate noted were $37 \%$, for a patients having submucosal and muscular invasions [40, 41]. Mortality in about $90 \%$ cases in SCC is from loco regional progression as a result of ureteric or bladder neck obstruction and renal failure. In NB-SCC, the distant metastases are uncommon, with an incidence of $8-10 \%$.

Lagwinski $\mathrm{N}$ et al observed, the recurrence and mortality rates of patients with transitional carcinomas with squamous differentiation are 2-4 fold higher than in patients without squamous differentiation respectively [15]. Dotson A et al study showed squamous cell carcinoma of the bladder shows poor response to neoadjuvant chemotherapy [32].

\section{Conclusion}

Squamous cell carcinoma (SCC) is an uncommon subtype of urinary bladder carcinoma.The clinical, histopathological,imm unocytochemistry and molecular biomarker evaluation for the biological process behind urinary bladder cancer is specific to SCC. It is necessary to understand SCC of the bladder better, especially for prognosis. The patients of SC urinary bladder often presents at advanced stage at diagnosis resulting in poor prognosis. The understanding of SCC urinary bladder and its clinical, histopathological and biomarker study will improve specific diagnosis. And it will be helpful to plan treatment strategies for better management of these patients.

\section{Acknowledgements}

NIL

\section{Ethical policy}

Approval was taken from institutional ethical committee. The study was performed in accordance with the Declaration of Helsinki. Patients gave their informed consent for their participation.

\section{Author contributions}

All authors have equally contributed to the manuscript.

\section{Competing interests}

NIL

\section{Funding}

NIL

\section{References}

1. Siegel RL, Miller KD, Jemal A. Cancer statistics, 2016.CA Cancer J Clin 2016; 66(1): 7-30.

2. Rausch S, Hofmann R, von Knobloch R. Nonbilharzial squamous cell carcinoma and transitional cell carcinoma with squamous differentiation of the lower and upper urinary tract. Urol Ann 2012; 4(1): 14-18.
3. Felix AS, Soliman AS, Khaled H, et al. The changing patterns of bladder cancer in Egypt over the past 26 years. Cancer Causes Control 2008; 19: 421-9.

4. Khare V, Kumar Jain V, Tantuway R. Study of Urothelial Neoplasm in Central India With Reference To WHO/ISUP Grading. Int J Med Res Rev, Internet 2013; 1(4): 177-83.

5. Moch H, Humphrey PA, Ulbright TM, Reuter V. WHO Classification of Tumours of the Urinary System and Male Genital Organs. Lyon, France: International Agency for Research on Cancer; 2016.

6. Jagtap SV, Beniwal A, Jagtap SS et. al. Transitional cell carcinoma with glandular differentiation - a rare variant of urinary bladder carcinoma. Int J Health Sci Res 2015; 5(1): 374-376.

7. Santos LL, Santos J, Gouveia MJ, Bernardo C, Lopes C, Rinaldi G, Brindley PJ, Costa JMCD. Urogenital Schistosomiasis- History, Pathogenesis, and Bladder Cancer. J Clin Med 2021; 8; 10(2): 205.

8. Dahm P, Gschwend JE. Malignant non-urothelial neoplasms of the urinary bladder: a review. Eur Urol 2003 Dec; 44(6): 672-81.

9. Navon J.D., Soliman H., Khonsari F., Ahlering T. Screening cystoscopy and survival of spinal cord injured patients with squamous cell cancer of the bladder. J Urol 1997; 157: 2109-2111.

10. Cho JH, Holley JL. Squamous cell carcinoma of the bladder in a female associated with multiple bladder stones. BMC Res Notes 2013; 4(6): 354.

11. Fernando MH, Jayarajah U, Herath KB, de Silva MVC, Goonewardena SAS. Aggressive squamous cell carcinoma of the bladder associated with a history of large bladder stone - a case report. Clin Case Rep 2017, 5(10): 1616-1619.

12. Youssef R., Kapur P., Kabbani W., Shariat S.F., Mosbah A., Abol- Enein H. Bilharzialvs non-bilharzial related bladder cancer: pathological characteristics and value of cyclooxygenase-2 expression. BJU Int 2011; 108:31-37

13. Shiraishi Y, Moroi S, Negoro H, Iwamura H, Oka H, Kawakita M. Squamous cell carcinoma of the bladder presenting with bladder rupture: a case report. Hinyokika Kiyo 2006; 52(2): 139-41.

14. Jagtap SV, Sarda SD, Demde RB, Huddedar AD, Jagtap SS. Primary Squamous Cell Carcinoma of Urinary Bladder - A Rare Histological Variant. J Clin Diagn Res 2015; 9(11): ED03-ED4.

15. Lagwinski N, Thomas A, Stephenson AJ, Campbell S,et al . Squamous cell carcinoma of the bladder: a clinicopathologic analysis of 45 cases. Am J Surg Pathol 2007; 31(12): 1777-87.

16. Eble JN, Epstein JI, Sauter G, et al. World Health Organisation Histologic and Genetic Typing of Tumors of the Kidney, Urinary Bladder, Prostate Gland and Testis. Lyon: IARC Press; 2004.

17. Manunta A., Vincendeau S., Kiriakou G., Lobel B., Guille F. Nontransitional cell bladder carcinomas. BJU Int 2005; 95: 497-502.

18. Spradling K, Abol-Enein H, Mosbah A., Okhunov Z, Landman J, Shokeir A. PD41-07 prognostic significance of lympho-vascular invasion in patients with squamous cell carcinoma in comparison to urothelial carcinoma of the bladder. J Urol 2015; 193:e842-e843.

19. S Vernez, K Spradling, J Morgan, et al .Prognostic value of lymphovascular invasion in squamous cell carcinoma of the urinary bladder.Journal of Clinical Oncology 2016; 34: 2_suppl, 450-454.

20. Gruver AM, Amin MB, Luthringer DJ, Westfall D, et al Selective immunohistochemical markers to distinguish between metastatic high-grade urothelial carcinoma and primary poorly differentiated invasive squamous cell carcinoma of the lung. Arch Pathol Lab Med 2012; 136(11): 1339-46.

21. Mariah Z. Leivo, Paul J. Elson, David E. Tacha, et al.A combination of p40, GATA-3 and uroplakin II shows utility in the diagnosis and prognosis of muscle-invasive urothelial carcinoma. Anatomical Pathology 2016; 48 (6): 543-549.

22. Gulmann C, Paner GP, Parakh RS, Hansel DE, et al. Immunohistochemical profile to distinguish urothelial from squamous differentiation in carcinomas of urothelial tract. Hum Pathol 2013; 44(2): 164-72.

23. Al-Sharaky DR, Abdelwahed M, Asaad N, Foda A, Abdou 
AG. Stratification of urinary bladder carcinoma based on immunohistochemical expression of CK5, CK14 and CK20. J Immunoassay Immunochem 2021; 42(3): 236-251.

24. Wenbin Huang, Sean R. Williamson QiuRao,Antonio Lopez- Beltran, Rodolfo Montironi et al . Novel markers of squamous differentiation in the urinary bladder. Human Pathology 2013; 44: 1989-1997.

25. Warrick JI, Sjödahl G, Kaag M, et al. Intratumoral Heterogeneity of Bladder Cancer by Molecular Subtypes and Histologic Variants. EurUrol 2019; 75: 18-22.

26. McConkey DJ, Choi W. Molecular Subtypes of Bladder Cancer Curr Oncol Rep 2018; 20: 77.

27. W Beukers, Kirstin A.van der Keur, R Kandimalla et al. FGFR3, TERT and OTX1 as a Urinary Biomarker Combination for Surveillance of Patients with Bladder Cancer in a Large Prospective Multicenter Study.The Journal of Urology 2017; 197(6): 1410-1418.

28. Juanpere N , Agell L, Lorenzo M , de Muga S , Lopez-Vilaro L, et al. Mutations in FGFR3 and PIK3CA, singly or combined with RAS and AKT1, are associated with AKT but not with MAPK pathway activation in urothelial bladder cancer. Hum Pathol 2012; 43(10): 1573-1582.

29. Zvereva M, Pisarev E, Hosen I, Kisil O, Matskeplishvili S, Kubareva E, Kamalov D, Tivtikyan A, Manel A, Vian E, Kamalov A, Ecke T, Calvez-Kelm FL. Activating Telomerase TERT Promoter Mutations and Their Application for the Detection of Bladder Cancer. Int J Mol Sci 2020; 21(17): 6034.

30. Cowan M, Springer S, Nguyen D, Taheri D, Guner G, Rodriguez MA, Wang Y, Kinde I, VandenBussche CJ, Olson MT, Cunha I, Fujita K, Ertoy D, Bivalacqua TJ, Kinzler K, Vogelstein B, Netto GJ, Papadopoulos N. High prevalence of TERT promoter mutations in primary squamous cell carcinoma of the urinary bladder. Mod Pathol 2016; 29(5): 511-555.

31. Tsutomu S and Chohei Sakakura. Overexpression of Cyclooxygenase-2 in Squamous Cell Carcinoma of the Urinary Bladder Clin Cancer Res 2001; 7 (3): 558-561.

32. Dotson A, May A, Davaro F, Raza SJ, Siddiqui S, Hamilton $Z$. Squamous cell carcinoma of the bladder: poor response to neoadjuvant chemotherapy. Int J Clin Oncol 2019; 24(6): 706-711.

33. Robertson, A Gordon et al. "Comprehensive Molecular Characterization of Muscle-Invasive Bladder Cancer.” Cell 2017; 171(3) : 540-556.

34. Gonzalez-Zuulueta $\mathrm{M}$,ShibataA,Ohneseit PE et al.High frequency of chromosome 9p allelic loss and CDKN2tumor suppression gene alterations in SCC of the urinary bladder. JNatlCancerInst 1995; 87(18):1383-93.

35. Maia MC, Hansen A, Alves C, Salah S.Biomarkers in NonSchistosomiasis-related squamous cell carcinoma of the urinary bladder: A review.Critical Reviews in Oncology Hematology 2019; 135: 76-84.

36. Ewis AA, El-Samman E, Ali N, Kajimoto K, Shinohara Y, Ishikawa M, Kanayama HO, Baba Y. Gene expression profile in squamous cell carcinoma of the urinary bladder using complementary deoxyribonucleic acid microarray. Urol Oncol 2007; 25(2): 120-127.

37. Babjuk M, Böhle A, Burger M, Capoun O, Cohen D, CompératEM,etal.EAU Guidelines on Non-Muscle-invasive Urothelial Carcinoma of the Bladder: Update 2016. Eur Urol 2017; 71(3): 447-461.

38. Ploeg M, Aben KK, Hulsbergen-van de Kaa CA, Schoenberg MP, Witjes JA, Kiemeney LA. Clinical epidemiology of nonurothelial bladder cancer: analysis of the Netherlands Cancer Registry. J Urol. 2010; 183(3): 915-920.

39. Matulay JT, Woldu SL, Lim A, Narayan VM, Li G, Kamat AM, Anderson CB. The impact of squamous histology on survival in patients with muscle-invasive bladder cancer. UrolOncol 2019; 37(6): 353.e17-353.e24.

40. Fasal MH .Squamous cell carcinoma of the bladder. J Urol 1981;
126(5): 598-599.

41. Shokeir A.A. Squamous cell carcinoma of the bladder: pathology, diagnosis and treatment. BJU Int 2004; 93: 216-220. 